Acta Poetica 25-1

PRIMAVERA

2004

\title{
Gerardo Deniz
}

\section{Tolhausen}

Hace casi medio siglo descubrimos en el Fondo de Cultura Económica que nuestro viejo diccionario alemán-español era un verdadero tesoro. Bastaba abrirlo para caer en absurdos y extravagancias. Años más tarde, inicié el repaso metódico del libro. Fue un largo camino. Al término de mis afanes, era evidente que el caso del diccionario de Tolhausen era mucho más complicado y sorprendente de lo que pareció durante años enteros. Publiqué dos artículos al respecto en la revista de la Biblioteca de México. Pero hacen falta más comentarios. Ahora está siendo capturada la totalidad del material que recogí, y espero prologarlo como es debido. Por el momento, he aquí un botón de muestra.

Babelgedanke.- Concepto grandioso, heroico, que hiere la imaginación.

Babine. - Piel bruna del gato ruso.

Back.- Tina en que se sirve la comida de cada rancho de gente.

Backhuhn.- Gallina armada.

Badekarren.- Carro cubierto para bañar en la mar.

Badeschrank.- Aparato para chorros. 
Bagatellsachen.- Pleitos de simple policía.

Bahamaeinhorn.- Monoceronte escrito.

Bahrrecht.- Antiguo derecho de buscar el asesino emplazando los suspectos delante del féretro del matado.

Bakelmann.- Él que tiene el abedul para castigar los muchachos. Balg.- Camisa de la culebra y serpiente.

Balkanhalbinsel.- Península de los Balcanos.

Ballon.- Castaña forrada de esparto para ácidos.

Ballot.- Votación por bolitas en Inglaterra.

Bambuse.- Marinero tímido.

Bandaxt.- Herramienta para vaciar una mortaja.

banktüchtig.- Bueno por ser vendido en la tabla de carnicería.

bänkeln.- Jugar del faraón.

einen bösen Geist in irgend einen Teil des Leibes eines Besessenen bannen.- Ligar.

Barettaffe.- Mono radiado.

barfuss gehen.- Andar en piernas.

sich um des Kaisers Bart zanken.- Meterse en la renta del excusado.

Bartneige.- Trago de vino que se da a él que ha faltado a alguna etiqueta en la mesa.

Bartwachs.- Cabo de olor para los bigotes.

Bassenach.- Pueblo de Lujemburgo.

sich auf den Bauch legen, indem man sich mit Händen und

Füssen an den Boden stemmt.- Ponerse en veinte uñas.

Bauerplatting.- Cajeta hecha de nueve hilos de acarrete. ungeschlachteter Bauernschrot.- Villano harto de ajos.

Baumkunst.- Arte de mudar la natura de los árboles.

bebeissen.- Decentar mordiendo.

sich beeicheln.- Cubrirse de bellotas.

unerwartete Begebenheit.- Fenomenón.

Begehen.- Perpetración de un crimen, celebración de una fiesta. aus dem Stegreif begleiten.- Acompañar de repente.

Beglerbeg.- Belerbeg. 
beglotzen.- Mirar con ojos esparrancados.

die Fährte begrasen.- Seguir con el dedo la huella del ciervo.

Begum.- Principesa índica.

behohnlächeln.- Fisgar sonriéndose.

er kam bei der Belagerung von Zaragoza um.- Murió sobre el sitio de Zaragoza.

Beihäu. - Carne de falda que mezcla el carnicero con la buena, haciéndola pagar al mismo precio.

Beischmack.- Gusto heterogéneo.

allgemein bekannt.- Más conocido que la rueda familiar.

bekielen.- Poner cabitos de pluma en las teclas de un clavicordio.

Bekrittelei.- Critiquizamiento.

bekünsteln.- Poner artificial.

belatten.- Clavar las latas a las vigas de un techo para forjarle.

belecken.- Lamer con la lengua.

belfern.- Ladrear sin cesar y sin objeto.

bemützen.- Tocar la cabeza.

beniesen.- Confirmar estornudando.

bepflätschern.- Rociar murmurando un arroyo.

beredsam.- Elocuente, que produce los mismos efectos que un discurso elocuente.

bereinigen.- Purgar (en estilo cancilleresco).

Bergkratze.- Rascador de los Alpes.

Bergschatte.- Escosés serrano.

beringen.- Cerrar con candado a la yegua para que no se cubre el garañón.

Beritt.- Distrito que ha de visitar un oficial acabalgado.

Berlinerzimmer.- Pequeño cuarto de esquina medio oscuro.

Bernsteinalabaster.- Succinato de albastro.

Bernsteinkammer.- Tribunal para las contiendas entre los pescadores del ámbar.

Bernsteinweinstein.- Tártaro succínico.

berosten.- Cubrirse de orina. 
bersten.- Escribirse el barniz, los colores de un cuadro.

berühren.- Interesar una llaga.

beschalmen.- Clavar las latas de los encerados.

beschindeln.- Cubrir de tablillas (en lugar de tejos).

Beschlagkitt.- Luto infusible.

beschocken.- Imponer una cuota por sesentena.

ein junges Mädchen als ältere Begleiterin beschützen.- Poner

a cubierto con su compañía la conducta de una joven.

beschwänzen.- Guarnecer de un rabo.

Besiegen.- Vencimiento de las pasiones.

besocken.- Echar suelas nuevas a las medias.

die festen Bestandteile des menschlichen Körpers.- Los sólidos.

Bestellanstalt.- Expedición central de los libreros.

bethlehemitischer Kindermord.- Degollación de los Innocentos. sich bethun.- Ensuciarse de sus inmondicias.

Bettzwillich.- Cuadros de Francia, Hamburgo y Holanda.

Bettelbrief.- Permisión para perdiosar.

Bentelperïcke.- Peluca con talega.

die Märkte, Jahrmärkte, Messen beziehen.- Visitar a menudo, girar las fieras.

Bierkomment.- Reglas de los estudiantes alemanos en bebiendo.

Bierreise.- Visita sucesiva de todas las tabernas de una población.

Bildertrödler.- Chalán de mamarrachos.

Birnquitte.- Membrillo femenino.

Bläser.- Imán que repele el hierro.

eine Blässe haben, die bis aufs Maul herabgeht.- Beber con

blanco las caballerías. 